\title{
Climatology and time series of surface meteorology in Ny-Ålesund, Svalbard
}

\author{
M. Maturilli ${ }^{1}$, A. Herber ${ }^{2}$, and G. König-Langlo ${ }^{2}$ \\ ${ }^{1}$ Alfred Wegener Institute for Polar and Marine Research, Potsdam, Germany \\ ${ }^{2}$ Alfred Wegener Institute for Polar and Marine Research, Bremerhaven, Germany \\ Correspondence to: M. Maturilli (marion.maturilli@awi.de)
}

Received: 25 October 2012 - Published in Earth Syst. Sci. Data Discuss.: 15 November 2012

Revised: 15 March 2013 - Accepted: 22 March 2013 - Published: 12 April 2013

\begin{abstract}
A consistent meteorological dataset of the Arctic site Ny-Ålesund $\left(11.9^{\circ} \mathrm{E}, 78.9^{\circ} \mathrm{N}\right)$ spanning the 18 yr-period 1 August 1993 to 31 July 2011 is presented. Instrumentation and data handling of temperature, humidity, wind and pressure measurements are described in detail. Monthly mean values are shown for all years to illustrate the interannual variability of the different parameters. Climatological mean values are given for temperature, humidity and pressure. From the climatological dataset, we also present the time series of annual mean temperature and humidity, revealing a temperature increase of $+1.35 \mathrm{~K}$ per decade and an increase in water vapor mixing ratio of $+0.22 \mathrm{~g} \mathrm{~kg}^{-1}$ per decade for the given time period, respectively. With the continuation of the presented measurements, the Ny-Ålesund high resolution time series will provide a reliable source to monitor Arctic change and retrieve trends in the future.

The relevant data are provided in high temporal resolution as averages over 5 (1) min before (after) 14 July 1998, respectively, placed on the PANGAEA repository (doi:10.1594/PANGAEA.793046).

While 6 hourly synoptic observations in Ny-Ålesund by the Norwegian Meteorological Institute reach back to 1974 (Førland et al., 2011), the meteorological data presented here cover a shorter time period, but their high temporal resolution will be of value for atmospheric process studies on shorter time scales.
\end{abstract}

\section{Introduction}

On the background of global warming, temperature increase in the Arctic has been found to be nearly twice as large as the global average (IPCC, 2007). A variety of processes have been proposed to contribute to this amplified Arctic warming. Most prominent is the ice-albedo feedback mechanism associated with the current retreat and thinning of Arctic sea ice and resulting changes in surface heat fluxes (Curry et al., 1995; Lindsay and Zhang, 2005; Screen and Simmonds, 2010). Other aspects are the influence of cloud cover and water vapour (Schweiger et al., 2008; Wu and Lee, 2012), and increased meridional heat transport to the northern high latitudes related to changes in cyclone behaviour and atmospheric circulation patterns (Graversen et al., 2008; Zhang et al., 2008).
As the Arctic sea ice cover decline is occurring faster than most of the climate models predict (Stroeve et al., 2007, 2012), it is even more important to build on reliable atmospheric observation data from the Arctic region.

At the Arctic site Ny-Ålesund $\left(78.9^{\circ} \mathrm{N}, 11.9^{\circ} \mathrm{E}\right)$, the $\mathrm{Al}-$ fred Wegener Institute for Polar and Marine Research (AWI) operates surface radiation measurements as part of the Baseline Surface Radiation Network (BSRN) since August 1992. Collocated meteorological surface observations were initiated in August 1993, providing important auxiliary information to the radiation measurements (Kupfer et al., 2006). Considering Arctic climate change, these meteorological data meanwhile gain value as stand-alone climate datasets.

Here, we present a thorough description of the meteorological surface measurements in the period 1 August 1993 


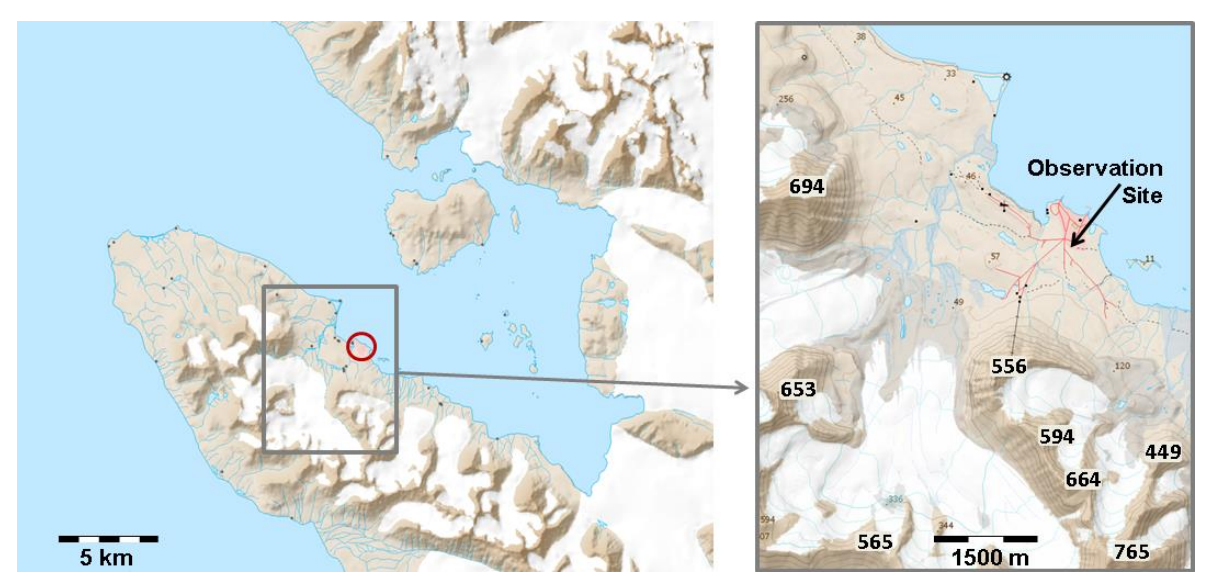

Figure 1. Left: topographic map of the Kongsfjord area on the western coast of Svalbard, the red circle indicating the location of Ny-Ålesund. Right: enlarged section of the Ny-Ålesund surroundings, with numbers indicating the elevation of mountain ridges in metre. The topographic maps were obtained from the Norsk Polarinstitutt via http://eivind.npolar.no/Geocortex/Essentials/Web.

to 31 July 2011 . These $18 \mathrm{yr}$ of observational data form the basis for a Ny-Ålesund atmospheric surface climatology.

\section{Ny-Ålesund surface meteorology dataset description}

Ny-Ålesund is located on the west coast of Svalbard (Spitsbergen), one of the northernmost archipelagos in the Arctic. The village is an international centre for various modern Arctic research activities, situated at a fjord surrounded by glaciers, moraines, rivers, mountains, and a typical tundra system. A topographic map of the Kongsfjord area and the closer surrounding of Ny-Âlesund is shown in Fig. 1, illustrating the complex environment influencing atmospheric processes on the micro- and mesoscale. With the special orography of surrounding mountains causing a tunnel effect along the Kongsfjord, Ny-Ålesund may not be a representative location for the general Arctic, but provides evidence for general Arctic variability and change when looking at synoptic time scales. Its high latitudinal position implies polar night condition between 24 October and 18 February, and polar day between 18 April and 24 August, respectively.

During the summer period, the terrain is snow-free, with the melt season starting around May/June, the onset of melting depending on the individual synoptic situation of each year. Snow-fall can also occur in summer, but the snow cover usually remains stable only after October. During recent winters, there have been several heavy precipitation periods with rain rather than snow.

In the southern part of Ny-Ålesund, AWI operates a $10 \mathrm{~m}$ meteorological tower, mounted on a measurement field with soft tundra ground. The horizontal distance to the closest building is about $220 \mathrm{~m}$, while a slightly elevated street with no traffic - is about $5 \mathrm{~m}$ to the other direction. To avoid effects of the growing village activities and to reduce poten- tial effects of the close by street ridge, the meteorological tower was shifted by $40 \mathrm{~m}$ in August 2011. In this climatology, we refer to data registered before this relocation to avoid potential effects on the dataset homogeneity. A detailed description of the different meteorological sensors and their time series is given below. A common feature of all parameters is the adjustment of the $5 \mathrm{~min}$ data registration to $1 \mathrm{~min}$ measurement intervals that was adapted since 14 July 1998 with a renewal of the data acquisition hardware.

Generally, the meteorological tower is inspected at least once per day by the observatory personnel to check for disturbances of the measurement, e.g. icing of the radiation shields or mechanical damage from reindeer or birds.

\subsection{Air temperature $2 \mathrm{~m}$ above solid ground}

In $2 \mathrm{~m}$ height above solid ground, a PT-100 resistance thermometer is mounted to monitor surface air temperature. The instrument is a product of the company "Thies Clima", with a double radiation shield and a built-in ventilator providing an air flow of $3.5 \mathrm{~m} \mathrm{~s}^{-1}$. The temperature range $-30{ }^{\circ} \mathrm{C}$ to $80{ }^{\circ} \mathrm{C}$ is covered with an accuracy of $\pm 0.1 \mathrm{~K}$ declared by the manufacturer. Lower temperatures are measured with a reduced accuracy. During the period 1 August 1993 to 31 July 2011 only minor changes were adapted to the instrumentation. The instrument was replaced by the same instrument type on 8 December 1994, on 6 February 1995, and on 27 May 1996 due to malfunction, while on 23 November 1998, only the ventilator was replaced. The instrument has been measuring in this configuration ever since.

For all meteorological parameters in this study, monthly mean values are calculated from daily mean values which are retrieved using the hourly mean values. Missing values in the observational data (e.g. due to malfunction of the instrument) are handled depending on their duration. If more than $50 \%$ (30 min) of data are missing within $1 \mathrm{~h}$, the hourly mean is 

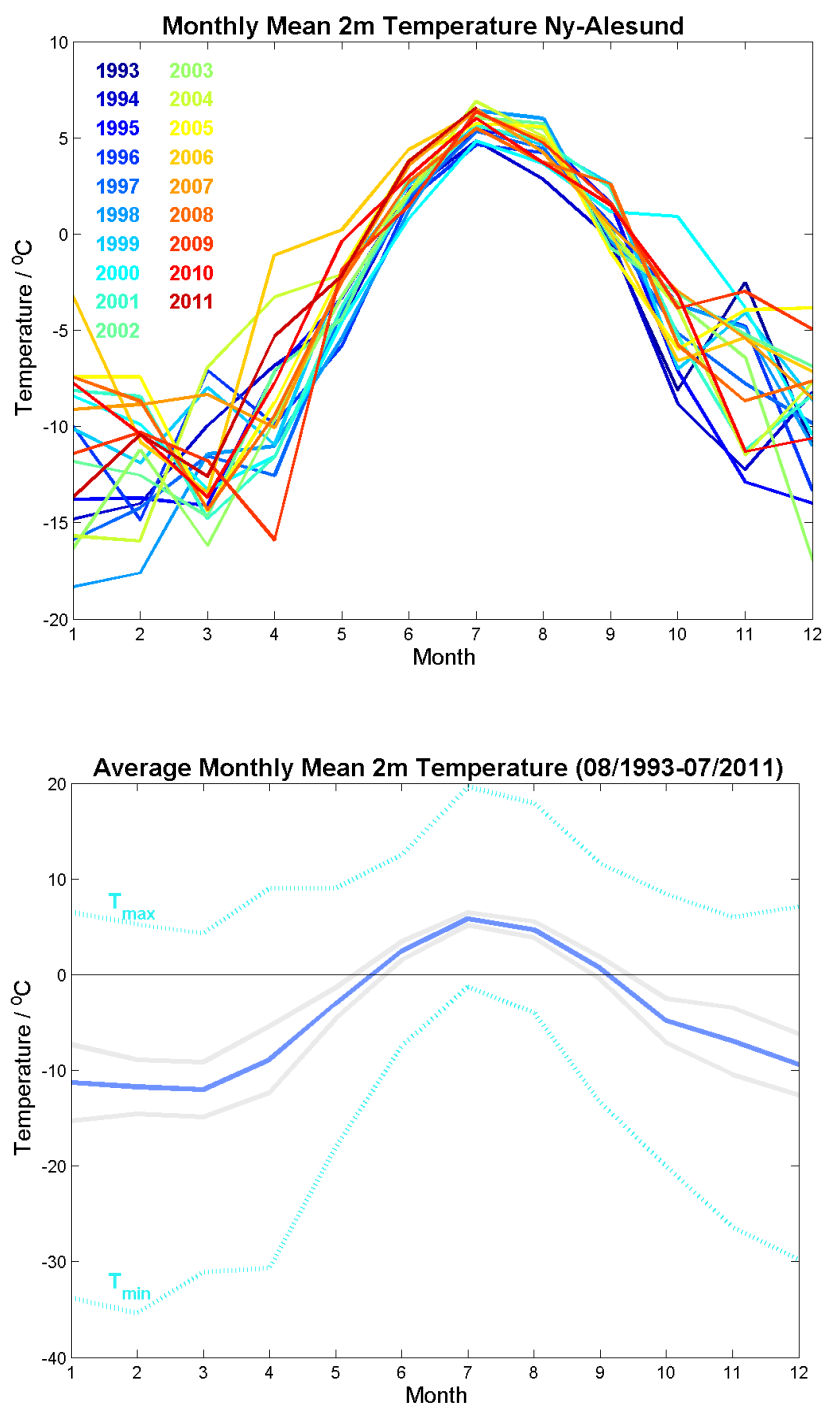

Figure 2. (a) Upper panel: monthly mean surface air temperature, colour-coded for the different years of the observation period. (b) Lower panel: averaged monthly mean surface air temperature \pm 1 standard deviation (dark blue and grey lines, respectively), as well as the monthly observed minimum and maximum temperatures from hourly data during the period August 1993 to July 2011 ( $T_{\min }$ and $T_{\max }$, blue dotted lines).

considered a missing hourly mean value. If more than $21 \%$ $(5 \mathrm{~h})$ of hourly mean values are missing within 1 day, the daily mean is considered a missing daily mean value. And respectively, if more than $12 \%$ ( $\sim$ days) of daily mean values are missing, the monthly mean is considered a missing monthly mean value. Considering these numbers, no missing monthly mean values have to be taken into account for the surface air temperature climatology.

In Fig. 2a, the monthly mean surface air temperature is shown for all years included in this study. Obviously, the inter-annual variability is much larger in winter than in summer, e.g. the mean January temperature ranges from -17.0
Table 1. Climatology of Ny-Ålesund surface air temperature, humidity and station-level pressure as calculated from average monthly mean values in the period 1 August 1993 to 31 July 2011.

\begin{tabular}{lrcc}
\hline Month & $\begin{array}{r}T \\
{\left[{ }^{\circ} \mathrm{C}\right]}\end{array}$ & $\begin{array}{c}\mathrm{H}_{2} \mathrm{O} \text { Mixing Ratio } \\
{\left[\mathrm{g} \mathrm{kg}^{-1}\right]}\end{array}$ & $\begin{array}{c}\text { Pressure } \\
{[\mathrm{hPa}]}\end{array}$ \\
\hline January & -11.3 & 1.4 & 1001.9 \\
February & -11.7 & 1.2 & 1005.8 \\
March & -12.0 & 1.2 & 1007.0 \\
April & -8.9 & 1.6 & 1011.8 \\
May & -3.0 & 2.3 & 1015.5 \\
June & 2.5 & 3.6 & 1011.8 \\
July & 5.8 & 4.7 & 1010.5 \\
August & 4.7 & 4.5 & 1011.0 \\
September & 0.6 & 3.3 & 1006.9 \\
October & -4.8 & 2.1 & 1007.7 \\
November & -7.0 & 1.9 & 1004.8 \\
December & -9.4 & 1.5 & 1003.1 \\
\hline
\end{tabular}

to $-3.8^{\circ} \mathrm{C}\left(\Delta T_{\text {mean }}=13.2 \mathrm{~K}\right)$, while the mean July temperature ranges from 4.6 to $6.9^{\circ} \mathrm{C}\left(\Delta T_{\text {mean }}=2.3 \mathrm{~K}\right)$. This difference in variability is also represented in Fig. 2b, showing the monthly mean values averaged over the whole time period along with the standard deviation. Usually, the summer months with monthly mean surface air temperature above the frost point are snow cover free. Yet, the minimum temperature shown in Fig. $2 \mathrm{~b}$ indicates that snowfall is possible also during the summer months, while the maximum temperature points to the possibility of rainfall during the winter months. The climatological monthly mean surface air temperatures are listed in Table 1.

On the same meteorological tower, temperature has also been measured in $10 \mathrm{~m}$ height above solid ground with an identical sensor. A replacement of this instrument or part of it occurred on 6 February 1995, on 29 July 1996, and on 21 September 1998 . The climatological monthly mean values are similar to those in $2 \mathrm{~m}$ height and not explicitly shown here. The data are included in the dataset.

\subsection{Surface atmospheric humidity ( $2 \mathrm{~m})$}

Humidity has been measured by two parallel sensors, both installed in $2 \mathrm{~m}$ height above solid ground. While in the first years, both humidity measurements were performed with a hair hygrometer, one of them (hereafter called RF1) was exchanged with a humicap sensor on 25 October 1999. After almost $3 \mathrm{yr}$ of parallel humicap and hair hygrometer measurements, the second humidity instrument (hereafter called RF2) was also exchanged with a humicap sensor on 28 July 2002.

The hair hygrometer instruments were Thies Clima hygrotransmitters with a weather and radiation shield. The measuring element was hair with a specific treatment to obtain the desired hygrometric characteristics, explicitly suitable for 
temperatures below freezing point. The measuring range was 10 to $100 \%$ relative humidity, with a manufacturer declared accuracy of $\pm 2 \%$ relative humidity in an ambient temperature of -35 to $70{ }^{\circ} \mathrm{C}$ as measured by a ventilated PT- 100 .

The succeeding humicap instruments are Vaisala humidity and temperature transmitters HMP233. Relative humidity is retrieved with a manufacturer declared accuracy of $\pm 1 \%$ $( \pm 2 \%)$ in the range of 0 to $90 \%$ (90 to $100 \%$ ) relative humidity, respectively, measured with HUMICAP $^{\circledR} \mathrm{K}$ in an ambient temperature of -40 to $80^{\circ} \mathrm{C}$ detected by PT100 RTD $1 / 3$. The according mixing ratio range is $0 \ldots 500 \mathrm{~g} \mathrm{~kg}^{-1}$ dry air.

Since 5 March 2002, the relative humidity with respect to water is calculated using the $2 \mathrm{~m}$ temperature measurement instead of the internal instrument temperature measurement, as similar measurements in Antarctica indicated radiative effects despite the radiation shield. The measured relative humidity at given internal temperature is used to retrieve the dew point temperature, a parameter that remains unaffected by radiative heating of the shelter. The obtained dew point temperature is combined with the external $2 \mathrm{~m}$ surface air temperature measurement to retrieve ambient relative humidity with respect to water. Thus, by applying this method we gain independence of radiative effects on the humidity shelter, and in fact the difference in relative humidity between the two sensors has been largely reduced. In any case, we estimate the uncertainty of the humidity measurements to be larger than the accuracy declared by the manufacturer, on the order of $10 \%$ relative humidity for the hair hygrometer and $5 \%$ relative humidity for the humicap sensors, less than $5 \%$ for the retrieval via dew point and external temperature. On 16 March 2002, the humicap sensor of RF1 was replaced with a new one. On 7 July 2004, the humicap sensor RF2 was also replaced, and both instruments were calibrated on site.

In our climatological study we refer only to RF1, as the fraction of missing data for RF2 is too high to produce representative mean values. Figure 3 a shows the monthly mean values of relative humidity for all years of the analysed period. While the data refer to relative humidity with respect to water, Fig. 3a highlights the average monthly mean relative humidity both with respect to water and with respect to ice, the latter calculated for temperatures below $0{ }^{\circ} \mathrm{C}$ from the 1 (5) min observation data. Figure $3 b$ traces the according $\mathrm{H}_{2} \mathrm{O}$ mixing ratio $\mu=0.622 \times e /(p-e)$, with $p=$ pressure and $e=$ vapor pressure. The amount of surface atmospheric humidity is driven by a combination of large scale advection and local evaporation and sublimation effects. As expected, the summer months are more humid than the winter months. Yet, absolute values reveal the dryness of Arctic air, with an average $\mathrm{H}_{2} \mathrm{O}$ mixing ratio summer maximum in July/August of about $4.6 \pm 0.3 \mathrm{~g} \mathrm{~kg}^{-1}$ over the entire period. The winter months (December/January/February) exhibit an average $\mathrm{H}_{2} \mathrm{O}$ mixing ratio of about $1.4 \pm 0.4 \mathrm{~g} \mathrm{~kg}^{-1}$. For the
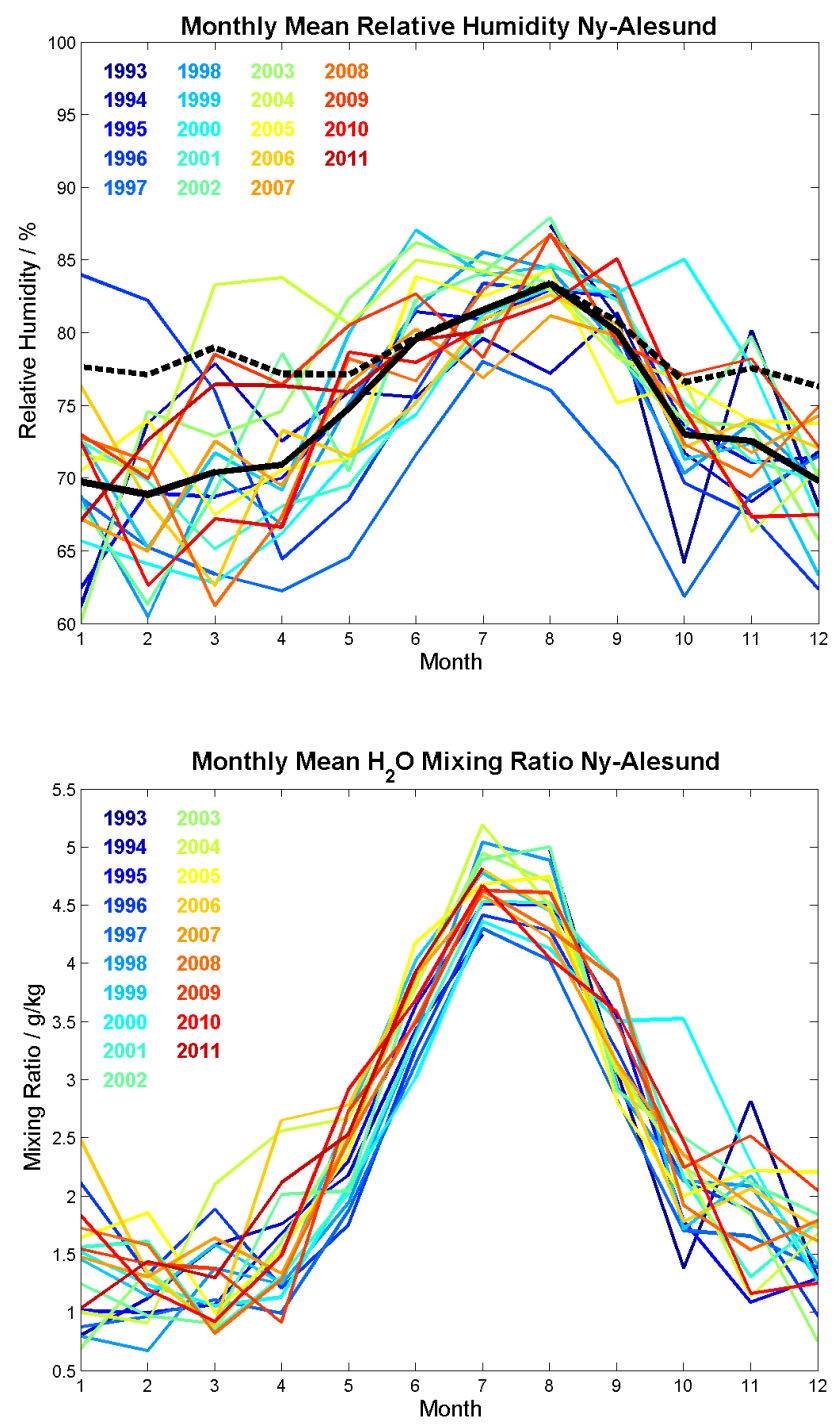

Figure 3. (a) Upper panel: monthly mean relative humidity with respect to water, black for the average over all years and colourcoded for the different years of the observation period. The black dashed line indicates the average monthly mean relative humidity with respect to ice. (b) Lower panel: monthly mean $\mathrm{H}_{2} \mathrm{O}$ mixing ratio, colour-coded for the different years of the observation period.

life cycle of aerosols, the extremely low winter humidity implicates that dry deposition becomes a relevant process. Yet, the variability of humidity in winter is large, and daily mean $\mathrm{H}_{2} \mathrm{O}$ mixing ratios up to $4.3 \mathrm{~g} \mathrm{~kg}^{-1}$ are possible, although not visible in the monthly mean values. The average monthly mean values are listed in Table 1.

\subsection{Station-level pressure}

Before the replacement of the meteorological tower in $\mathrm{Au}-$ gust 2011, the atmospheric pressure measurements were obtained from the "Blue House" building in Ny-Ålesund, at 

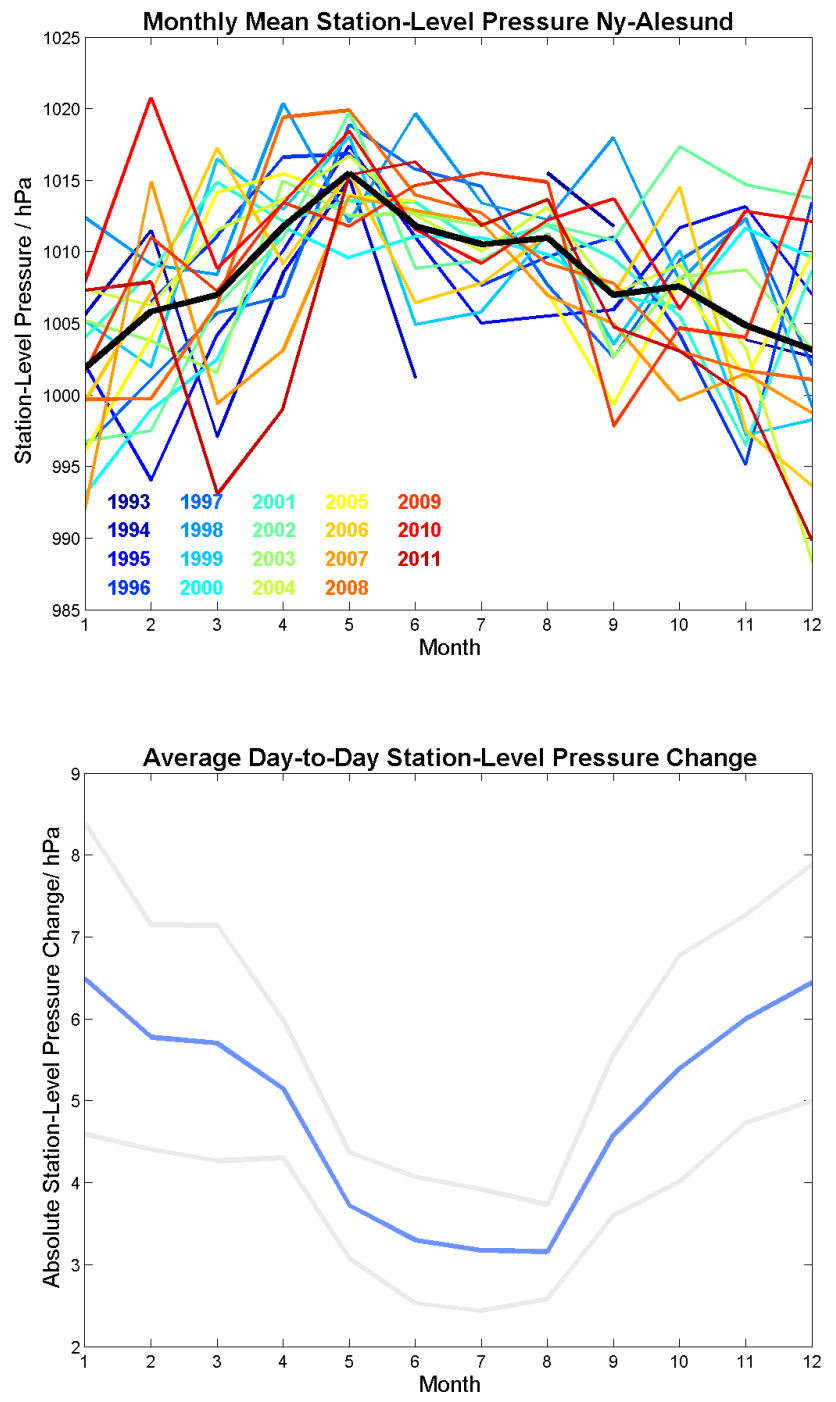

Figure 4. (a) Upper panel: monthly mean station-level pressure, colour-coded for the different years of the observation period and black for the average over all years. (b) Lower panel: averaged monthly mean station-level pressure day-to-day absolute change \pm 1 standard deviation (blue and grey lines, respectively).

$11 \mathrm{~m}$ a.s.l. in a horizontal distance of about $240 \mathrm{~m}$ from the meteorological tower.

During the first period of the time series, station-level pressure was registered with a Thies Clima digital baro transmitter with an aneroid capsule with inductive displacement pickup serving as a sensor, exchanged once on 29 December 1994. The measuring range was 913.3 to $1113.3 \mathrm{hPa}$, with a manufacturer declared accuracy of $\pm 0.5 \mathrm{hPa}$. On 19 January 1996, the instrument was exchanged with a Paroscientific Digiquartz ${ }^{\circledR}$ Pressure Sensor 740-16B, providing a barometric range accuracy of $\pm 0.08 \mathrm{hPa}$ declared by the manufacturer. No further changes have been applied to the stationlevel pressure measurement until the relocation of the meteorological tower and the pressure sensor in August 2011.
In Fig. 4a, the monthly mean station-level pressure values are shown for the analysed period. Due to the large amount of missing values, the months October 1993, July 1994, January 1996, and July 2005 are excluded from this climatological study. As the observed station-level pressure shows a very large month-to-month variation, the general annual evolution throughout the year is not necessarily apparent and therefore explicitly indicated. In fact, average monthly mean values exhibit only small differences between summer and winter, as given in Table 1. More relevant may be the mean day-to-day absolute change in station-level pressure shown in Fig. 4b, which indicates the dynamic of passing cyclonic systems. Pressure change from day-to-day is smaller during the summer months when pressure systems tend to have a smaller amplitude. In spring and autumn, daily pressure changes are increased, whereas the maximum of day-to-day pressure variability occurs in winter when passing cyclones have larger amplitudes in pressure gradient and their occurrence is more frequent. The enhanced cyclonic activity in winter is also reflected in the surface air temperature variability shown in Fig. 2.

\subsection{Wind speed and direction $(10 \mathrm{~m})$}

For the detection of wind speed and direction, a Thies Clima combined wind sensor classic has been installed in $10 \mathrm{~m}$ height above solid ground. The sensor is measuring wind speed and direction of the horizontal air flow with an extremely low threshold velocity. Its measuring range is 0.3 to $50 \mathrm{~m} \mathrm{~s}^{-1}$ for wind speed and 0 to $360^{\circ}$ for wind direction, with a manufacturer declared accuracy of $\pm 0.3 \mathrm{~m} \mathrm{~s}^{-1}$ or $\pm 2 \%$ of the measured value and $\pm 1.5^{\circ}$, respectively. It is designed for an ambient temperature range of -35 to $80{ }^{\circ} \mathrm{C}$.

The instrument or parts were exchanged on 29 August and 8 September 1998, as well as on 29 and 31 March 2000, and 29/30 August 2000. Due to a longer time period of malfunction prior to the instrument exchange, March and August 2000 are not considered in this climatological study as too many missing data affect the representativeness for these months, as also for September 1993.

As wind is a directional quantity, any averaging is little meaningful as opposing vectors will be cancelled out. Also, the large dynamic range of wind on a short time scale implies limitations to its representation in a climatological analysis. Turbulence and gusts are leveled out with averaging calculations, and their strength and frequency are not represented in the monthly or daily mean. We therefore consider hourly mean values, retrieved by vectorial averaging of the $5 \mathrm{~min}(1 \mathrm{~min})$ time-resolved raw data, assuming that synoptic scale air flow does not significantly change below these time scales. Figure 5 gives an impression of the general wind situation in Ny-Ålesund, showing the two-dimensional frequency distribution of wind speed and wind direction in percent for each month. 

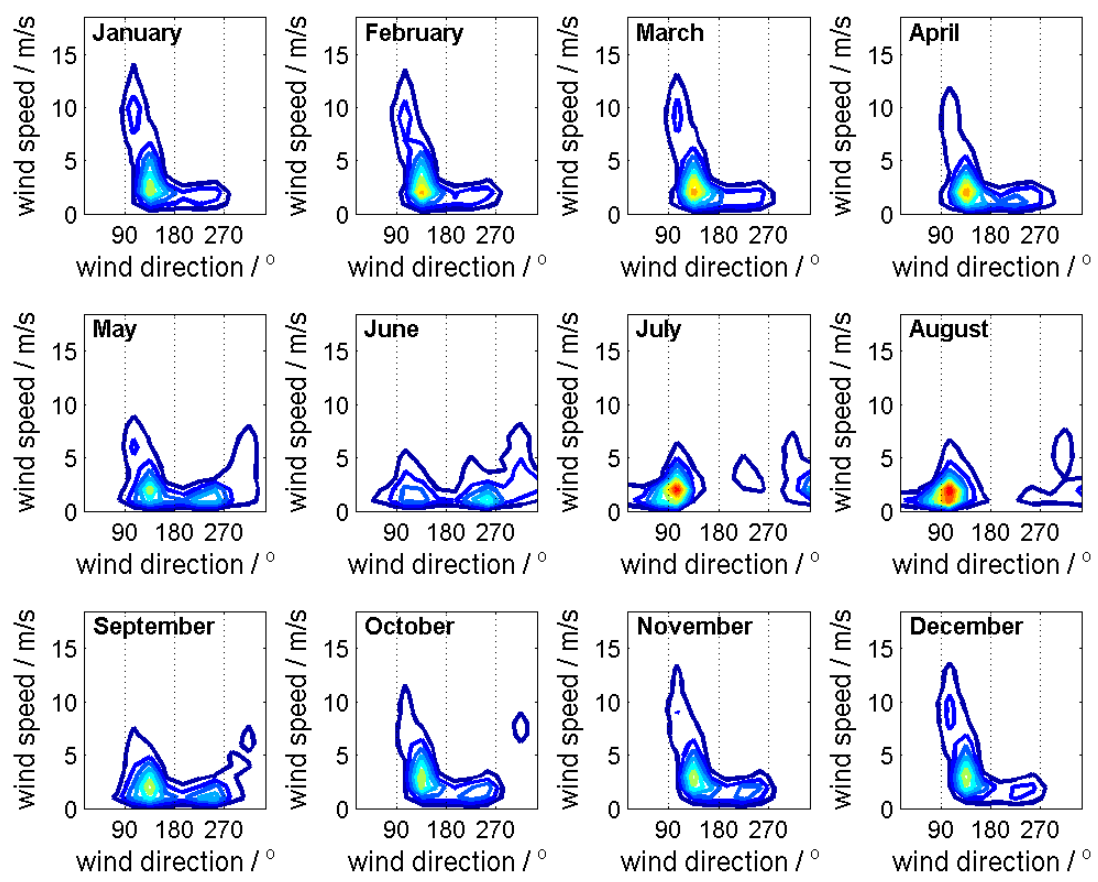

$-1 \%-2 \%-3 \%-4 \%-5 \%-6 \%-7 \%-8 \%-9 \%-10 \%-11 \%$

Figure 5. Monthly two-dimensional frequency distribution of wind speed and wind direction in percent for all hourly mean wind speed data exceeding $0.5 \mathrm{~m} \mathrm{~s}^{-1}$, covering the period August 1993 to July 2011. The class widths are $1 \mathrm{~m} \mathrm{~s}^{-1}$ and $30^{\circ}$, respectively.

The most prominent feature is the main wind direction from east/south-east (around $110^{\circ}$ ) which is present throughout the whole year, but with highest wind velocity in the cold period between autumn and spring. The high winter wind speed supports the assumption of enhanced cyclonic storm activity during this period of the year. Generally, strong wind with speed higher than $10 \mathrm{~m} \mathrm{~s}^{-1}$ almost exclusively arrives from east/south-east. The orientation of the main wind direction is related to the local orography influencing the synoptic atmospheric flow, with the fjord oriented in west-east direction surrounded by mountains channeling the wind. In addition, katabatic flow from the Kongsvegen glacier about $10 \mathrm{~km}$ east of Ny-Ålesund affects the predominant flow at the site (Beine et al., 2001).

A second frequently observed wind direction is from south-west (around $225^{\circ}$ ), related to katabatic outflow from the Brøggerbreen glaciers channeled along the slopes of the Zeppelin mountain range south of Ny-Ålesund. This southwesterly flow commonly has a slower wind speed $<5 \mathrm{~m} \mathrm{~s}^{-1}$, and together with strong temperature inversion is a main precondition for the formation of gravity waves during polar night conditions (Jocher et al., 2012).

While all other wind directions occur likewise all year around, wind from the North (around $0^{\circ} / 360^{\circ}$ ) is almost exclusively observed during the summer period, with velocities less than $5 \mathrm{~m} \mathrm{~s}^{-1}$. This wind from the fjord in the North towards the mountain in the South is likely to be a sea breeze formed by increasing temperature differences between the land and water, especially as it occurs only during the snowfree period of polar day.

An identical instrument is measuring wind at $2 \mathrm{~m}$ height above solid ground. The data are provided in the dataset, but not explicitly presented here due to their general similarity to the $10 \mathrm{~m}$-wind data.

\section{Examples for atmospheric processes on short scale}

Taking advantage of the high temporal resolution of the data, it is possible to resolve various atmospheric processes on short time scales. The local synoptic situation is reflected in the course of the meteorological surface measurements. Obviously, on the time scale of hours the pressure gradient indicates the approach or decline of high pressure systems or cyclones. Figure 6 shows the course of pressure, temperature, wind velocity and wind direction on 4 January 2009 as an example of a passing cyclone. The exact timing and dynamics of the passing cold front is understood by retracing the single observations. During the first half of the day, there is a drastic drop in station-level pressure, reaching its minimum at about noon. Along with a reduction in wind speed, there is a change in wind direction from south-east to northnorthwest at 12:30 UTC indicated by the dashed line. Some minutes later, the wind speed accelerates to reach $15 \mathrm{~m} \mathrm{~s}^{-1}$ within the next half hour. After the onset of high wind speed 

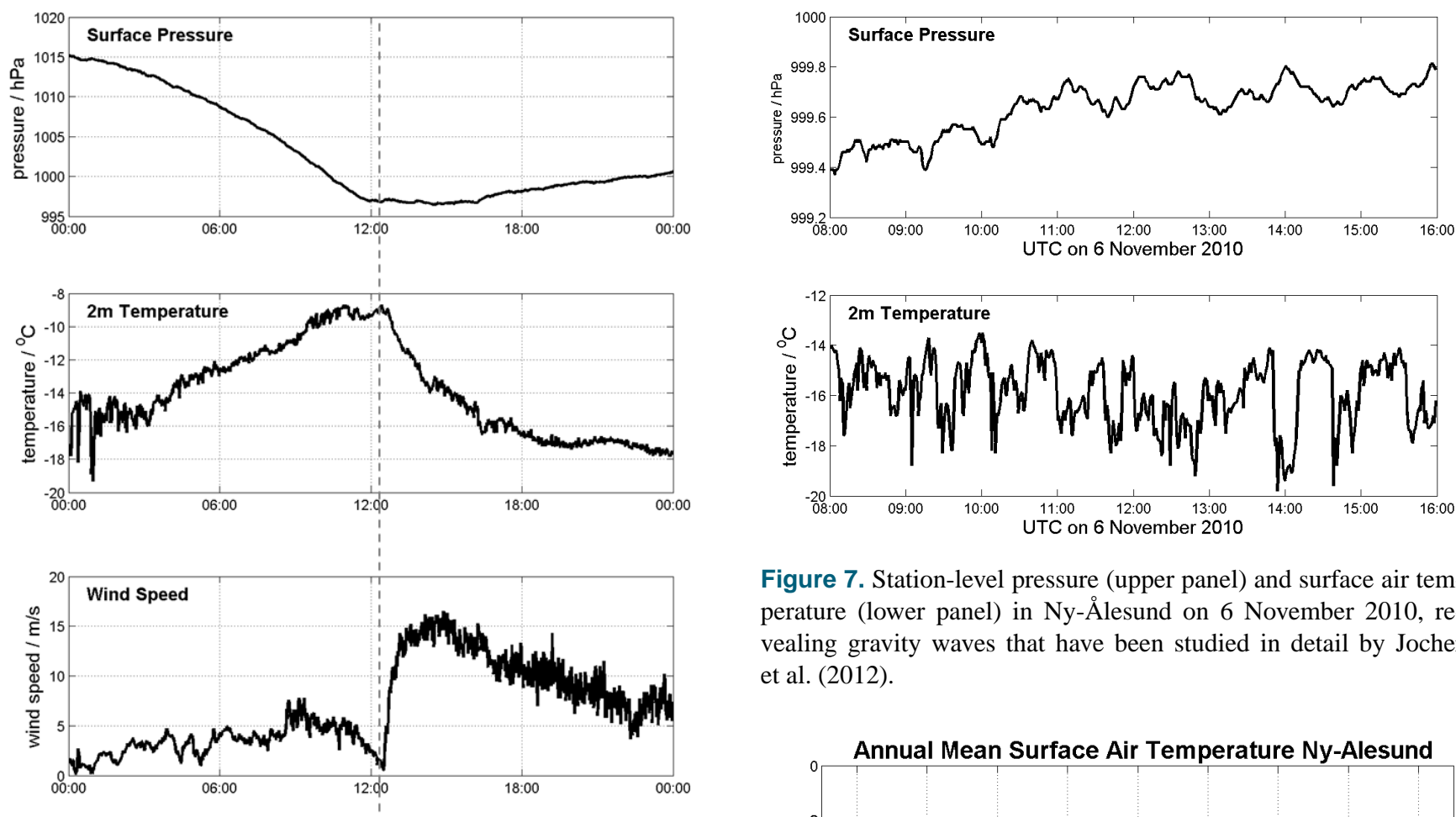

Figure 7. Station-level pressure (upper panel) and surface air temperature (lower panel) in Ny-Ålesund on 6 November 2010, revealing gravity waves that have been studied in detail by Jocher et al. (2012).

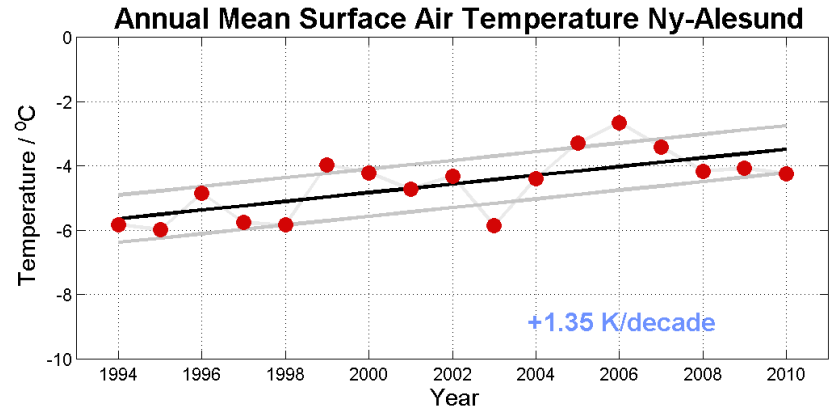

Figure 8. Annual mean of the $2 \mathrm{~m}$ surface air temperature in $\mathrm{Ny}$ Ålesund from 1994 to 2010 (red dots), with the linear regression \pm 1 standard deviation (black and grey lines, respectively) giving a temperature increase of $+1.35 \mathrm{~K}$ per decade. panel: station-level pressure, $2 \mathrm{~m}$ temperature, $10 \mathrm{~m}$ wind speed, and wind direction. The dashed vertical line indicates the onset of wind direction change.

from the new direction, temperatures drop dramatically as the cold front has passed and the cyclone's cold air sector has reached Ny-Ålesund. An example for microscale processes found in the data is given in Fig. 7. Here, station-level pressure and temperature are shown for an $8 \mathrm{~h}$ period on 6 November 2010, where wave-like variation is found for both variables. In fact, this polar-night case with clear-sky conditions, near-surface inversion and low wind velocity allowed for the development of gravity waves, externally triggered by katabatic outflow from a nearby glacier as shown by Jocher et al. (2012).

Generally, the dataset provides meteorological information with high time resolution as background for all $\mathrm{Ny}$ Ålesund projects studying atmospheric processes on short time scales.

\section{Time series}

The available $18 \mathrm{yr}$ of homogeneous observational data reflect ongoing changes in the Arctic climate system. Indeed, during the analysed time period August 1993 to July 2011, surface air temperature has increased. Figure 8 shows the annual mean temperature for the calendar years 1994 to 2010, as retrieved from the monthly mean temperatures presented above. Linear regression of this 17 complete years time series indicates a temperature increase of $1.35 \pm 0.92 \mathrm{~K}$ per decade in Ny-Ålesund during recent years. Though covering a shorter time period, this increase is in accordance with the trend obtained using the synoptical observations done in $\mathrm{Ny}$ Ålesund by the Norwegian Meteorological Institute reaching back to 1974 (Førland et al., 2011). With a systematic quality and homogeneity check of the continuing high resolution temperature data collection, the Ny-Ålesund time series will gain an additional source for the retrieval of Arctic 


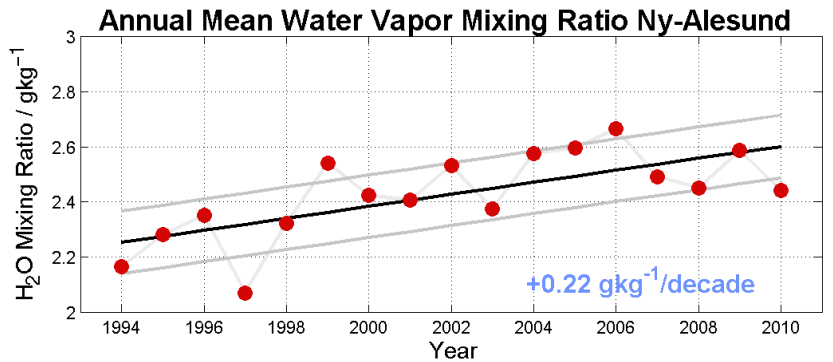

Figure 9. Annual mean of the $\mathrm{H}_{2} \mathrm{O}$ mixing ratio in Ny-Ålesund from 1994 to 2010 (red dots), with the linear regression \pm 1 standard deviation (black and grey lines, respectively) giving a humidity increase of $+0.22 \mathrm{~g} \mathrm{~kg}^{-1}$ per decade.

temperature trends in the future, also allowing for the analysis of short-scale dynamics.

The observed increase in temperature is accompanied by an increase in absolute humidity. To avoid an effect of missing monthly mean pressure values, the annual mean $\mathrm{H}_{2} \mathrm{O}$ mixing ratio has been calculated using the average annual mean pressure value of $1008.15 \mathrm{hPa}$ over the entire period. Figure 9 shows the annual mean $\mathrm{H}_{2} \mathrm{O}$ mixing ratio for 1994 to 2010 , with the linear regression revealing an increase of $0.22 \pm 0.14 \mathrm{~g} \mathrm{~kg}^{-1}$ per decade. These observed changes in sensible and latent heat are part of the complex changes in the Arctic climate system, related both to large scale advection by atmospheric circulation systems and to local effects as enhanced evaporation above open water.

The observed slight increase in relative humidity is not significant due to the large scatter of the annual mean values and the according high standard deviation. Concerning wind, the two-dimensional frequency distribution of wind speed and wind direction for the first and the second half of the measurement period have been subtracted from one another to identify potential changes in the wind pattern over time, but no significant changes were found. Looking at days with high wind velocities (e.g. $10 \mathrm{~m} \mathrm{~s}^{-1}$ or $15 \mathrm{~m} \mathrm{~s}^{-1}$ in at least one hourly mean value), no significant change in the frequency of occurrence was found in the $18 \mathrm{yr}$ record. Also station-level pressure data give no indication of change during the last two decades.

\section{Summary}

A homogeneous dataset of high resolution meteorological parameter from Ny-Ålesund, Svalbard, for the period August 1993 to July 2011, was assembled for the use as climatological data. The quality-checked data of surface air temperature, humidity, wind speed and direction (all in 2 and/or $10 \mathrm{~m}$ height above solid ground, respectively) as well as station-level pressure are available online at doi:10.1594/PANGAEA.793046, including the simultaneous BSRN radiation measurements. The data provide an insight to the climatology of an Arctic land-based station at about $79^{\circ} \mathrm{N}$. With their high temporal resolution, they are suited as database for atmospheric process studies on small time scales. Furthermore, the meteorological data contribute to the study of changes in the Arctic with focus on alpine/marine landscape, and the continuation of their acquisition will enable the achieve trend analysis for this delicate region in the climate system.

Acknowledgements. Many thanks are expressed to the station personnel of the AWIPEV research base (former Koldewey station) in $\mathrm{Ny}$-Ålesund for their contribution to maintain the instrumentation hardware and software infrastructure. We thank in particular B. Loose for planning, erecting and updating the measurement site, J. Graeser for technical maintenance of the meteorological instrumentation and S. Debatin for data handling.

Edited by: D. Carlson

\section{References}

Beine, H. J., Argentini, S., Maurizi, A., Mastrantonio, G., and Viola, A.: The local wind field at Ny-Ålesund and the Zeppelin mountain at Svalbard, Meteorol. Atmos. Phys., 78, 107-113, 2001.

Curry, J. A., Schramm, J., and Ebert, E. E.: On the sea ice albedo climate feedback mechanism, J. Climate, 8, 240-247, 1995.

Førland, E. J., Benestad, R., Hanssen-Bauer, I., Haugen, J. E., and Skaugen, T. E.: Temperature and precipitation development at Svalbard 1900-2100, Adv. Meteorol., 2011, 893790, doi:10.1155/2011/893790, 2011.

Graversen, R. G., Mauritsen, T., Tjernström, M., Källén, E., and Svensson, G.: Vertical structure of recent Arctic warming, Nature, 451, 53-56, 2008.

Intergovernmental Panel on Climate Change (IPCC): Climate Change 2007: The Physical Science Basis, edited by: Solomon, S., Qin, D., Manning, M., Chen, Z., Marquis, M., Averyt, K. B., Tignor, M., and Miller, H. L., Cambridge Univ. Press, New York, 2007.

Jocher, G., Karner, F., Ritter, C., Neuber, R., Dethloff, K., Oberleitner, F., Reuder, J., and Foken, T.: The near-surface small-scale spatial and temporal variability of sensible and latent heat exchange in the Svalbard region: a case study, ISRN Meteorology, 2012, 357925, doi:10.5402/2012/357925, 2012.

Kupfer, H., Herber, A., and König-Langlo, G.: Radiation Measurements and Synoptic Observations at Ny-Alesund, Svalbard. Reports on Polar Research, 538, Alfred Wegener Institute for Polar and Marine Research, Bremerhaven, doi:10013/epic.10543.d001, 2006.

Lindsay, R. and Zhang, J.: The thinning of the Arctic sea ice, 19882003: Have we passed a tipping point?, J. Climate, 18, 48794894, doi:10.1175/JCLI3587.1, 2005.

Schweiger, A. J., Lindsay, R. W., Vavrus, S., and Francis, J. A.: Relationships between Arctic sea ice and clouds during autumn, J. Climate, 21, 4799-4810, 2008.

Screen, J. A. and Simmonds, I.: The central role of diminishing sea ice in recent Arctic temperature amplification, Nature, 464, 1334-1337, 2010. 
Stroeve, J., Holland, M. M., Meier, W., Scambos, T., and Serreze, M.: Arctic sea ice decline: Faster than forecast, Geophys. Res. Lett., 34, L09501, doi:10.1029/2007GL029703, 2007.

Stroeve, J. C., Kattsov, V., Barrett, A., Serreze, M., Pavlova, T., Holland, M., and Meier, W. N.: Trends in Arctic sea ice extent from CMIP5, CMIP3 and observations, Geophys. Res. Lett., 39, L16502, doi:10.1029/2012GL052676, 2012.

Wu, D. L. and Lee, J. N.: Arctic low cloud changes as observed by MISR and CALIOP: Implication for the enhanced autumnal warming and sea ice loss, J. Geophys. Res., 117, D7, doi:10.1029/2011JD017050, 2012.
Zhang, X., Sorteberg, A., Zhang, J., Gerdes, R., and Comiso, J. C.: Recent radical shifts of atmospheric circulations and rapid changes in Arctic climate system, Geophys. Res. Lett., 35, L22701, doi:10.1029/2008GL035607, 2008. 